\title{
Hidden treasures: the moulage museum in Zurich
}

\author{
Medical students still learn about skin diseases from hundreds of wax models that also record early cancer \\ research and the ravages of syphilis, reports Alison Abbott.
}

The last moulageuse produced her final work in 1963. Elsbeth Stoiber, creator of wax models at the University Hospital in Zurich, fought against a waning interest in her art when colour photography became cheap in the 1950s. Thanks to her efforts, a fine collection of some 1,800 models has survived - now housed in a new light-filled museum that seems part sanctuary, part horror-movie props room.

Using wax to represent the manifestations of disease in three dimensions became popular in the late nineteenth century. Practitioners of this art, known as medical moulage, guarded their methods closely. Many took their secrets to the grave.

The general technique involved making a plaster cast directly on a patient's diseased skin, filling the cast with waxes and resins, adding different coloured waxes to mimic scabs and glass bubbles to look like blisters, and finally inserting hairs individually. The result preserved for posterity, and in sublime detail, the particular stages of a disease - a godsend for medical teaching. But the procedure was arduous and required great skill, so only rich clinics could produce models in large numbers.

Stoiber relinquished her methods reluctantly, first at a medical conference in 1979, where she outlined the main steps. In 1998, accepting with a heavy heart that she really was the end of the line, she inducted the curator of the Zurich moulage collection in her recipes, art and science.

The Zurich recipes have turned out to be the most durable. Other important collections, such as those in Paris and Tokyo, have not retained their true colours. And the Second World War also finished off or depleted many other collections, either through bombing, as in Dresden, or because of poor storage. At Guy's Hospital in London, for example, the world's oldest collection was bunkered during the war in damp cellars, and a fungus infested many pieces.

The moulage collection at the University of Zurich was started in 1917, shortly after Bruno Bloch founded a dermatology clinic there. After decades of doldrums, interest was again revived in the 1980s. At first, historians had a hard time making sense of the collection. The models were labelled only with patients' names and dates of birth, the relevant medical records having long since been destroyed. Fortunately, careful library research united many objects with their histories: in the moulage era, great value was placed on publishing long case studies.

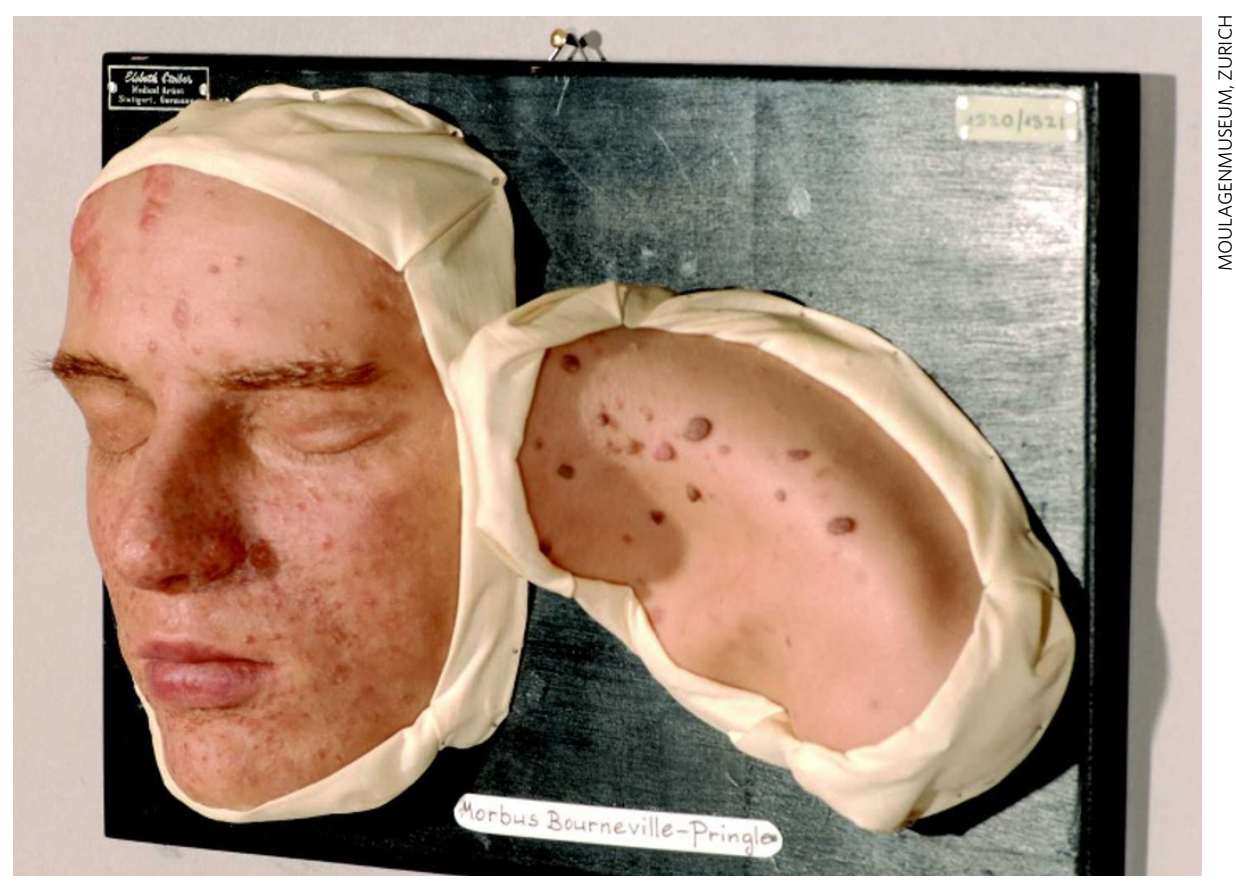

Wax casts immortalized skin diseases such as tuberous sclerosis in lifelike detail.

Further investigation revealed that the Zurich moulages had been made for medical research as well as for the more customary teaching function. Many pieces record rare side-effects of drugs, the consequences of emerging surgical techniques, and results of basic experiments.

Moulages showing symptoms of venereal diseases, such as syphilis and gonorrhoea, served several purposes. Models were made of the facial deformities of women infected with syphilis, who were locked into wards during treatment. These moulages were often used in alarming health propaganda to discourage promiscuity.

The incarcerated women also took part in research. A 17-year-old girl, for example, is immortalized in a moulage that shows skin reactions on her hands after deliberate infection with a foot fungus - an early demonstration of late-type sensitization of the immune system.

The Zurich collection records the first observations that X-rays, brought into medical use in 1897, can cause cancer as well as cure it. Medical expectations for X-rays were initially very high. One moulage shows a skin area scarred with psoriasis; a second model of the same area made some years after X-ray therapy shows the skin now covered with an oozing carcinoma. Novel surgical therapies, such as varicose vein removal and plastic surgery, are documented through to their long-term, often unhappy, consequences.

Other exhibits are a snapshot of early basic research into cancer, recording, for example, the long-term effects of painting tar onto the skin of mice, and exposing rabbits' ears to $\mathrm{X}$-rays. Bloch also had moulages made of the experiments he did on himself, and proved that eczema can sometimes result from an allergic reaction to external agents. Particularly shocking are the powerfully realistic models of diseases, such as tuberculosis, that were prevalent before the advent of antibiotics.

Today, Zurich medical students still enjoy practising their red-spot recognition skills in the museum. They find the moulages more intuitive than pictures or images on computer screens for assessing subtle differences in the surface manifestation of diseases. The public may take a more voyeuristic look on Wednesday and Saturday afternoons.

Alison Abbott is Nature's senior European correspondent.

See www.moulagen.ch for details.

For more Hidden treasures see www.nature.com/ nature/focus/hiddentreasures 